\title{
Clonidine for the prevention of emergence agitation in young children: efficacy and recovery profile
}

\author{
SHOBHA MALVIYA MD*, TERRI VOEPEL-LEWIS MSN RN*, \\ RADHAMANGALAM J. RAMAMURTHI MD, CONSTANCE \\ BURKE BSN RN* AND ALAN R. TAIT PhD* \\ *Department of Anesthesiology, University of Michigan Medical Center, Ann Arbor, MI and \\ tDepartment of Anesthesiology, Stanford University Medical Center, Stanford, CA, USA
}

\section{Summary}

Background: Emergence agitation (EA) is a common postoperative problem in young children who have received sevoflurane and isoflurane for general anesthesia. This randomized, double-blinded study evaluated the efficacy of intraoperative clonidine in reducing EA, and describes its recovery profile.

Methods: With Institutional Review Board approval and informed consent, children undergoing brief, minimally painful procedures were studied. All children received preemptive analgesia with acetaminophen and ketorolac, sevoflurane for induction, and isoflurane for maintenance of anesthesia. Children received either $2 \mu \mathrm{g} \cdot \mathrm{kg}^{-1}$ clonidine or placebo intravenously (i.v.) following induction of anesthesia. Children were observed postoperatively for behavior and side effects, and their parents were telephoned the next day to determine postdischarge recovery characteristics.

Results: One hundred and twenty children were included in this study: 59 of whom received clonidine, and 61 placebo; $41 \%$ of those in the placebo group exhibited moderate-severe EA compared with only $22 \%$ of those in the clonidine group $(P<0.03)$. Compared with those who received placebo, children who received clonidine awakened more slowly (22 min vs $14 \mathrm{~min}$ ), had a longer postanesthesia care unit stay (57 $\mathrm{min}$ vs $46 \mathrm{~min}$ ), and experienced sleepiness more frequently after discharge ( $75 \%$ vs $39 \%$; all comparisons significant at $P<0.03$ ). There were no adverse cardiorespiratory events in either group.

Conclusions: Findings demonstrate that i.v. clonidine administered after induction of anesthesia significantly reduces the incidence of EA in young children, but is associated with sleepiness postoperatively.

Keywords: emergence agitation; young children; clonidine 


\section{Introduction}

Emergence agitation (EA) which occurs in $18-80 \%$ of children following general anesthesia can be severe and prolonged, and may pose a risk for injury, pain and bleeding (1-4). While EA remains a poorly understood phenomenon, a variety of potential etiologies including pain, anxiety, and disorientation on rapid awakening have been implicated (59). A number of analgesic and sedative agents have been reported to reduce the incidence of EA to varying degrees $(7,10-13)$. The $\alpha_{2}$-adrenoceptor agonist, clonidine, has been administered via the oral, intravenous (i.v.) and caudal routes in attempt to prevent EA with mixed findings regarding its risk/benefit profile $(14,15)$. Bock et al. showed that both i.v. and caudal clonidine prevented EA without affecting time to discharge readiness (14). On the contrary, Fazi et al. (15) found higher excitement and pain scores in children who received oral clonidine compared with midazolam.

The objectives of this randomized controlled study were to evaluate: (i) the effectiveness of i.v. clonidine in reducing EA in children undergoing brief otologic or pulse dye laser procedures, and (ii) the recovery profile of children following clonidine administration.

\section{Methods}

With approval from the University of Michigan Institutional Review Board and written consent from parents, healthy children aged 2-10 years undergoing minor otologic or pulse dye laser procedures were studied. Children with a medical history of cardiovascular disease, neurologic impairment, sensitivities to clonidine or ketorolac, or who required premedication with midazolam were excluded from participation.

All children were given oral acetaminophen (15 $\mathrm{mg} \cdot \mathrm{kg}^{-1}$ ) approximately $30 \mathrm{~min}$ preoperatively, and ketorolac $\left(0.5 \mathrm{mg} \cdot \mathrm{kg}^{-1}\right.$ i.v.) following induction of general anesthesia for preemptive analgesia. General anesthesia was induced with nitrous oxide, oxygen, and sevoflurane (progressive increase to $8 \%$ ) via facemask, and maintained with isoflurane via mask or laryngeal mask airway. The child's behavior at induction was scored by the anesthesiologist using a three-point scale $(1=$ calm,
$2=$ slightly anxious or $3=$ uncooperative). Parental presence at induction was permitted at the discretion of the anesthesiologist. Using a table of random numbers, children were assigned $a$ priori to receive either $2 \mu \mathrm{g} \cdot \mathrm{kg}^{-1}$ of clonidine or an equal volume of normal saline to be administered i.v. immediately following induction and i.v. line placement. All care providers were blinded to group assignment. Intraoperative vital signs, medications administered, and complications were recorded.

Children were observed throughout their stay in the postanesthesia care unit (PACU). Pain was scored by each child's bedside nurse on arousal and at scheduled intervals throughout the PACU stay in accordance with routine practice using the Faces Legs Activity Cry Consolability (FLACC) behavioral observation tool (16), and treated for pain scores $>3$ of a total score of 10 . Trained observers scored the child's level of agitation using a previously described four-point scale $(1,5,7,12)$ where $0=$ quiet, calm; $1=$ mildly agitated but consolable; 3 = moderately agitated, nonpurposeful and inconsolable; and $4=$ severely agitated. Additionally, specific types of behavior were noted, and the bedside nurse was asked to subjectively qualify whether the agitation was indicative of delirium. Lastly, all pharmacologic and nonpharmacologic interventions, use of physical restraint, the onset and end of agitation, and the time of discharge to home were recorded.

Parents were telephoned the next business day to obtain information about the quality of recovery during the $24 \mathrm{~h}$ after surgery. Using a structured interview, parents were asked to rate postoperative sleepiness, agitation, aggression, anxiety, fear, or nightmares as (i) none, (ii) somewhat or (iii) extreme. Behavior that were scored as somewhat or extreme were followed up to determine the duration of the abnormal behavior (i.e. $<4,4-8$ or $>8$ h). Parents were also asked to describe any adverse events that may have occurred since discharge.

Data were analyzed using SPSS software (version13, Chicago, IL, USA), and are presented as $n(\%)$ or mean \pm SD as appropriate. Parametric data such as age, duration of anesthesia and recovery, and duration of agitation were compared using unpaired $t$-tests. Nonparametric data such as degree and incidence of agitation were compared using the chi-squared test with Fisher's exact tests where 
appropriate. $P$-values of $<0.05$ were considered as significant. A sample size calculation determined that 60 children per group were required $(\alpha=0.80$, $\beta=0.05)$ to demonstrate that clonidine would reduce the incidence of EA from $36 \%$, based on a previously reported incidence to $18 \%$ for children undergoing otologic procedures.

\section{Results}

One hundred and thirty-three children were recruited for this study. However, six children required premedication, two had medical exclusions, in three cases i.v. cannulation was not obtained, one procedure was more extensive than planned and one was cancelled. These cases were excluded from the study, and data are therefore presented for the remaining 120 children. Five children in the clonidine group and six in the placebo group refused the oral acetaminophen preoperatively; however, these children were included in the final analyses. The demographics of children in the clonidine and placebo groups were similar (Table 1).

A similar number of children in the clonidine and placebo groups had a parent present at induction $[n=30(54 \%)$ vs $35(57 \%)$, respectively]. Additionally, a similar number of children were rated as uncooperative at induction [18 (32\%) vs $20(33 \%)]$. None of the children in the study experienced a clinically significant change in blood pressure or vital signs. The postoperative outcomes of the study groups are presented in Table 2, and Figure 1 compares the degree of agitation observed on awakening. Children who received clonidine exhibited moderate to severe agitation less frequently in the PACU; however, their time to arousal and duration of PACU stay were longer. The nurses qualified the

Table 1

Description of the study groups

\begin{tabular}{lcc}
\hline & Clonidine $(\mathrm{n}=59)$ & Placebo $(\mathrm{n}=61)$ \\
\hline Age (years) & $3.6 \pm 2.3$ & $3.7 \pm 2.3$ \\
Weight $(\mathrm{kg})$ & $16.8 \pm 6.2$ & $17.2 \pm 6.3$ \\
Male/female & $41(70 \%) / 18(30 \%)$ & $46(75 \%) / 15(25 \%)$ \\
ASA-PS I/II & $42(71 \%) / 17(29 \%)$ & $47(77 \%) / 14(23 \%)$ \\
$\begin{array}{l}\text { Surgical procedure } \\
\text { (otologic/pulse }\end{array}$ & $54(92 \%) / 5(8 \%)$ & $55(91 \%) / 6(9 \%)$ \\
dye laser) & & \\
\hline
\end{tabular}

ASA-PS, American Society of Anesthesiologists Physical Status.
Table 2

Outcomes of the study groups

\begin{tabular}{lll}
\hline & $\begin{array}{l}\text { Clonidine } \\
(\mathrm{n}=59)\end{array}$ & \multicolumn{1}{c}{$\begin{array}{c}\text { Placebo } \\
(\mathrm{n}=61)\end{array}$} \\
\hline Anesthesia duration (min) & $22.2 \pm 9.4$ & $21.6 \pm 7.9$ \\
Change in SBP from baseline & $-9 \pm 24.4$ & $-4.4 \pm 18.3$ \\
Time to arousal $^{\mathrm{a}}$ (min) & $22.3 \pm 16.5$ & $14.4 \pm 14.8^{\mathrm{b}}$ \\
Moderate to severe agitation $^{\text {Duration of agitation (min) }}$ & $13(22 \%)$ & $25(41 \%)^{\mathrm{b}}$ \\
Length of PACU stay (min) $_{\text {Outcomes following discharge }}^{\mathrm{c}}$ & $9.1 \pm 10.4$ & $11.3 \pm 8.8$ \\
Excessive sleepiness $_{\text {Agitation or aggression }}$ & $n 6.9 \pm 20.6$ & $46.1 \pm 16.2^{\mathrm{b}}$ \\
Anxiety & $39(75 \%)$ & $n=53$ \\
Nightmares & $3(6 \%)$ & $5(39 \%)$ \\
\hline
\end{tabular}

SBP, systolic blood pressure; PACU, postanesthesia care unit. ${ }^{a}$ Time to arousal is defined as time from anesthetic off to first response. ${ }^{\mathrm{b}} P \leq 0.03$.

'Several parents could not be reached after surgery; percentage reflects total respondents.

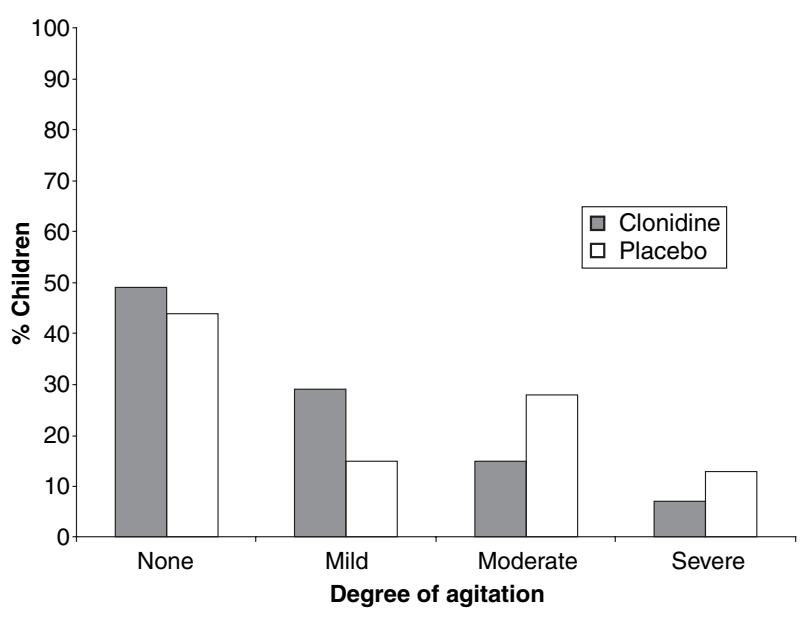

Figure 1

Comparison of the degree of agitation between study groups.

agitation as delirium for only six $(10 \%)$ children in the clonidine group, compared with $16(26 \%)$ in the placebo group $(P=0.02)$. Only 13 children $(22 \%)$ who received clonidine compared with $24(39 \%)$ in the placebo group required physical restraint for protection $(P=0.04)$. However, similar numbers of children in both groups [i.e. six $(10 \%)$ in the clonidine vs four $(7 \%)$ in the placebo group; $P=\mathrm{NS}$ ] required morphine or codeine for observed pain during their recovery stay.

Significantly more children who received clonidine experienced sleepiness after discharge compared with the placebo group. However, excessive 
sleepiness resolved for the majority of children $(72 \%)$ in $<4 \mathrm{~h}$. There were no differences between groups in other postdischarge behavior or in perioperative or postoperative adverse outcomes including hypotension, pain, nausea, or dizziness. Moderate to severe agitation was associated with increased bleeding from the surgical site in two children, one in each study group, and with premature dislodgement of an i.v. line in one child in the placebo group. Across both the groups, children with moderate to severe agitation were significantly younger compared with those with none-mild agitation $(2.9 \pm 1.8$ vs $4.2 \pm 2.3$ years, respectively, $P=0.001$ ).

\section{Discussion}

The results of this study demonstrate that $2 \mu \mathrm{g} \cdot \mathrm{kg}^{-1}$ of clonidine administered i.v. following anesthesia induction significantly reduces the incidence of EA without altering hemodynamic parameters in children undergoing brief surgical procedures. However, its use was associated with increased time to awakening and duration of PACU stay, as well as reported sleepiness after discharge.

Previous investigators have reported a high incidence of agitation following exposure to shortacting anesthetics during brief, minimally invasive or noninvasive procedures $(2,9,10,17-20)$. These findings suggest that mechanisms other than pain may contribute to EA in children. Such mechanisms may include psychological immaturity, genetic predisposition, anxiety and temperament $(2,5,6,9)$. Additionally, it could be postulated that anesthesia-related depression of inhibitory centers in the central nervous system, or an imbalance of neurotransmitters such as serotonin, dopamine and acetylcholine may be responsible, in part, for the occurrence of EA. Similar etiologies have been described for paradoxical reactions to benzodiazepines and barbiturates $(21,22)$. The purported effect of $\alpha_{2}$-agonists in preventing EA may support this hypothesis, given their effects in reducing noradrenergic output from the locus ceruleus and thereby facilitating the firing of inhibitory neurons such as the $\gamma$-aminobutyric acid system (23). Indeed, several reports have shown that administration of clonidine or dexmedetomidine, significantly reduced the incidence of EA in children undergoing minor procedures (14,24-26). Our findings similarly suggest a beneficial effect of $\alpha_{2}$-agonist agents in reducing EA in children.

Previous studies that have evaluated the use of $\alpha_{2}-$ agonist agents to prevent EA suggest differing mechanisms for their effects. For example, Guler et al. found that children undergoing adenotonsillectomy who received dexmedetomidine had a lower incidence of severe pain and required rescue opioids less frequently compared with placebo, suggesting an analgesic effect in reducing EA (26). Alternatively, Bock et al. attempted to rule out pain as the source of EA by administering caudal bupivacaine to all children in their study, and by differentiating pain from delirium using a specific assessment technique (14). From these and similar studies, it remains difficult to discern whether the analgesic or sedative effects of $\alpha_{2}$-agonists are responsible for reducing EA in children. In our study, we included procedures associated with minimal pain, treated potential pain preemptively, and separately assessed for postoperative pain using a validated tool. In addition, nurses subjectively qualified delirium behaviors based on their prior experience. Our findings that both groups required rescue analgesics with similar frequency and that both EA and delirium were reduced in the clonidine group suggest a nonanalgesic mechanism for these effects. As the etiology of EA is likely multimodal, however, administration of $\alpha_{2}$-agonists, regardless of their mechanism, remains a good alternative to reduce or treat EA.

The $\alpha_{2}$-agonists have been shown to have dosedependent effects on heart rate and blood pressure. Previous studies have reported statistically, but not clinically significant differences in these hemodynamic variables in children who received 2$3 \mu \mathrm{g} \cdot \mathrm{kg}^{-1}$ of clonidine i.v. or caudally $(14,27)$. Similarly, we found no significant changes in heart rate or blood pressure in either group. However, in our study, children who received clonidine $\left(2 \mu \mathrm{g} \cdot \mathrm{kg}^{-1}\right.$ i.v.) experienced longer times to awakening and PACU discharge, and sleepiness for several hours following discharge. While two studies have found no significant difference in time to awakening (27) or fitness for discharge (14) in children receiving 2-3 $\mu \mathrm{g} \cdot \mathrm{kg}^{-1}$ clonidine i.v., Bergendahl et al. reported excessive sleepiness following discharge in children who received rectal clonidine $\left(5 \mu \mathrm{g} \cdot \mathrm{kg}^{-1}\right)(28)$. 
Interestingly, parents of children in this study reported a preference for their children to be asleep and calm rather than awake and alert following discharge. Furthermore, excessive sleepiness has not been associated with other serious side effects such as respiratory depression.

The newer $\alpha_{2}$-receptor agonist, dexmedetomidine, that possesses an eightfold greater degree of specificity for the $\alpha_{2}$-vs the $\alpha_{1}$-receptor and has a shorter half-life compared with clonidine (2-3 h vs $12-24 \mathrm{~h}$, respectively), may be associated with less postoperative sedation. Studies to date have not reported its effects on postdischarge sleepiness, but have shown no clinically significant delay in time to eye opening or to PACU discharge following its use $(25,26)$. While the pharmacologic profile of dexmedetomidine might suggest an improved risk/benefit ratio over clonidine for the prevention of EA, comparative data are as yet unavailable.

This study demonstrated that i.v. clonidine administered after induction of anesthesia significantly reduced the incidence of EA in young children, but was associated with sleepiness postoperatively. This study has addressed the prophylactic use of clonidine to minimize the occurrence of EA. The potential use of $\alpha_{2}$-agonists in treating EA as recently suggested, requires further investigation.

\section{References}

1 Voepel-Lewis T, Burke C, Hadden SM et al. Nurses' diagnoses and treatment decisions regarding care of the agitated child. J Perianesth Nurs 2005; 20: 239-248.

2 Voepel-Lewis T, Malviya S, Tait AR. A prospective cohort study of emergence agitation in the pediatric postanesthesia care unit. Anesth Analg 2003; 96: 1625-1630.

3 Olympio MA. Postanesthetic delirium: historical perspectives. J Clin Anesth 1991; 3: 60-63.

4 Veyckemans F. Excitation phenomena during sevoflurane anaesthesia in children. Current Opinion in Anaesthesiology 2001; 14: 339-343.

5 Aono J, Ueda W, Mamiya K et al. Greater incidence of delirium during recovery from sevoflurane anesthesia in preschool boys. Anesthesiology 1997; 87: 1298-1300.

6 Wells LT, Rasch DK. Emergence 'delirium' after sevoflurane anesthesia: a paranoid delusion? (see comments). Anesth Analg 1999; 88: 1308-1310.

7 Finkel JC, Cohen I, Hannallah RS et al. The effect of intranasal fentanyl on the emergence characteristics after sevoflurane anesthesia in children undergoing surgery for bilateral myringotomy tube placement. Anesth Analg 2001; 92: 1164-1168.

8 Welborn LG, Hannallah RS, Norden JM et al. Comparison of emergence and recovery characteristics of sevoflurane, des- flurane, and halothane in pediatric ambulatory patients. Anesth Analg 1996; 83: 917-920.

9 Cole JW, Murray DJ, McAllister JD et al. Emergence behaviour in children: defining the incidence of excitement and agitation following anaesthesia. Paediatr Anaesth 2002; 12: 442-447.

10 Davis PJ, Greenberg JA, Gendelman M et al. Recovery characteristics of sevoflurane and halothane in preschool-aged children undergoing bilateral myringotomy and pressure equalization tube insertion. Anesth Analg 1999; 88: 34-38.

11 Fan K-T, Lee T-H, Tsung-Hsing K-L et al. Influences of tramadol on emergence characteristics from sevoflurane anesthesia in pediatric ambulatory surgery. Kaohsiung J Med Sci 2000; 16: 255-260.

12 Galinkin JL, Fazi LM, Cuy RM et al. Use of intranasal fentanyl in children undergoing myringotomy and tube placement during halothane and sevoflurane anesthesia. Anesthesiology 2000; 93: 1378-1383.

13 Lapin SL, Auden SM, Goldsmith LJ et al. Effects of sevoflurane anaesthesia on recovery in children: a comparison with halothane. Paediatr Anaesth 1999; 9: 299-304.

14 Bock M, Kunz P, Schreckenberger $\mathrm{R}$ et al. Comparison of caudal and intravenous clonidine in the prevention of agitation after sevoflurane in children. Br J Anaesth 2002; 88: 790796.

15 Fazi L, Jantzen EC, Rose JB et al. A comparison of oral clonidine and oral midazolam as preanesthetic medications in the pediatric tonsillectomy patient. Anesth Analg 2001; 92: 56-61.

16 Merkel SI, Voepel-Lewis T, Shayevitz JR et al. The FLACC: a behavioral scale for scoring postoperative pain in young children. Pediatr Nurs 1997; 23: 293-297.

17 Cravero J, Surgenor S, Whalen K. Emergence agitation in paediatric patients after sevoflurane anaesthesia and no surgery: a comparison with halothane. Paediatr Anaesth 2000; 10: 419-424.

18 Cravero JP, Beach M, Dodge CP et al. Emergence characteristics of sevoflurane compared to halothane in pediatric patients undergoing bilateral pressure equalization tube insertion. J Clin Anesth 2000; 12: 397-401.

19 Davis PJ, Cohen IT, McGowan Jr FX et al. Recovery characteristics of desflurane vs halothane for maintenance of anesthesia in pediatric ambulatory patients. Anesthesiology 1994; 80: 298-302.

20 Cravero JP, Beach M, Thyr B et al. The effect of small dose fentanyl on the emergence characteristics of pediatric patients after sevoflurane anesthesia without surgery. Anesth Analg 2003; 97: 364-367.

21 van der Bijl P, Roelofse JA. Disinhibitory reactions to benzodiazepines: a review. J Oral Maxillofac Surg 1991; 49: 519-523.

22 Stoelting R. Barbiturates. In: Stoelting R, ed. Pharmacology and Physiology in Anesthetic Practice, 2nd edn. Philadelphia: JB Lippincott Co., 1991: 108.

23 Tobias JD, Berkenbosch JW, Russo P. Additional experience with dexmedetomidine in pediatric patients. South Med J 2003; 96: $871-875$.

24 Levanen J, Makela ML, Scheinin H. Dexmedetomidine premedication attenuates ketamine-induced cardiostimulatory effects and postanesthetic delirium. Anesthesiology 1995; 82: 1117-1125.

25 Ibacache ME, Munoz HR, Brandes V et al. Single-dose dexmedetomidine reduces agitation after sevoflurane anesthesia in children. Anesth Analg 2004; 98: 60-63. 
26 Guler G, Akin A, Tosun Z et al. Single-dose dexmedetomidine reduces agitation and provides smooth extubation after pediatric adenotonsillectomy. Pediatr Anesth 2005; 15: 762-766.

27 Kulka PJ, Bressem M, Tryba M. Clonidine prevents sevoflurane-induced agitation in children. Anesth Analg 2001; 93: 335338 .
28 Bergendahl HT, Lonnqvist PA, Eksborg S et al. Clonidine vs midazolam as premedication in children undergoing adenotonsillectomy: a prospective, randomized, controlled clinical trial. Acta Anaesthesiol Scand 2004; 48: 1292-1300.

Accepted 26 October 2005 